\title{
Pré-resfriamento na redução de coliformes em carcaças de frango de corte
}

\author{
Immersion chilling in fecal coliforms count reduction on broiler carcasses
}

\author{
Vanessa Silva Simas ${ }^{I}$ Felipe Faccini dos Santos ${ }^{I^{*}}$ Raquel Gouvêa ${ }^{I}$ \\ Maria Helena Cosendey de AquinoII Dayse Lima da Costa AbreuI \\ Elmiro Rosendo do Nascimento ${ }^{\text {II }}$ Virginia Léo de Almeida Pereira ${ }^{I I}$
}

RESUMO

O objetivo deste trabalho foi comparar a análise individual (plano de duas classes) e a análise por lotes (plano de três classes), priorizado pelo plano amostragem oficial da ANVISA, na influência do pré-resfriamento de carcaças de frangos de corte na redução da contaminação por coliformes termotolerantes. Foram analisadas 240 carcaças de frangos de corte, sendo coletadas 120 amostras antes e 120 após a etapa de préresfriamento, para quantificação de coliformes termotolerantes pela técnica de contagem em placas. As médias das contagens obtidas das carcaças coletadas antes e após o pré-resfriamento foram diferentes, com uma redução média de 0,99 $\log _{10}$ UFC $g^{-1}$ de coliformes termotolerantes. Na interpretação dos resultados obtidos antes do pré-resfriamento pela análise individual, 16,7\% (20/120) das carcaças foram classificadas como inaceitáveis, enquanto, pela análise por lotes, foram 37,5\% (45/120). Houve associação entre a aceitabilidade dos lotes e a passagem pelo chiller com um valor de Odds Ratio de 35,48. Ficou demonstrada a importância da utilização do plano de análise por lotes e da etapa de pré-resfriamento no processo de produção, sendo decisivos para a aceitação dos lotes de carcaças de aves para comercialização pelos parâmetros vigentes na legislação nacional.

Palavras-chave: descontaminação, controle de qualidade de alimentos, chiller, termotolerantes, plano amostral.

\section{ABSTRACT}

The objective of this study was to assess the influence of immersion chilling on broiler carcasses contamination by fecal coliforms counting in a poultry slaughterhouse under Federal Sanitary Inspection by individual and three class plan interpretation of the results. Two hundred and forty broiler carcasses, being collected 120 before and 120 after passage thought chillers, were analyzed for coliform counting by plate count technique.
The averages of the counts obtained from all carcasses collected before and after immersion chilling were different, with an average reduction of $0.99 \log _{10}$ CFU g $g^{-1}$ of fecal coliforms. Regarding individual results (two class plan) before chilling, 16.7\% (20/120) of the carcasses were classified as unacceptable, against $37.5 \%$ (45/120) regarding lots results (three class plan). There was a strong association between the acceptability of lots and immersion chilling with an Odds Ratio value of 35.48. It was demonstrated the importance of the official sampling plan and immersion chilling in the production process, being decisive for the acceptance of the chicken carcass lots by the national legislation standards.

Key words: decontamination, food quality control, chillers, termotolerant, sampling plan.

\section{INTRODUÇÃO}

No ranking mundial de produção de animais para abate, a criação de frangos está como a segunda colocada, só ultrapassada pela produção de suínos. O Brasil é o terceiro maior produtor e maior exportador de carne de frango desde o ano de 2004 (UBABEF, 2011). Diante desse panorama, o mercado internacional exige o monitoramento sanitário dos plantéis avícolas, além do controle da qualidade da carne de frango e seus derivados. Além disso, o mercado interno de produtos avícolas passou a exigir alto padrão de qualidade e segurança dos produtos fornecidos.

A segurança e qualidade dos alimentos, inclusive da carne in natura, pode ser estimada pela

IPrograma de Pós-graduação em Medicina Veterinária, Higiene Veterinária e Processamento Tecnológico de Produtos de Origem Animal, Faculdade de Veterinária, Universidade Federal Fluminense (UFF), 24230-340, Niterói, RJ, Brasil. E-mail: felipefaccini@vm.uff.br. *Autor para correspondência.

IIDepartamento de Saúde Coletiva Veterinária e Saúde Pública, Faculdade de Veterinária, Universidade Federal Fluminense (UFF), Niterói, RJ, Brasil. 
contagem de microrganismos aeróbios mesófilos, coliformes, Escherichia coli e microrganismos psicrotróficos, grupos considerados como indicadores. A contagem de coliformes pode estimar falhas na higiene durante o processamento e indicar contaminação de origem fecal, sendo que elevadas contagens desses microrganismos podem estar relacionadas a níveis significativos de enteropatógenos (JAY, 2000).

Entre as etapas críticas no processamento de carcaças de aves, destaca-se o pré-resfriamento, com a função principal de retardar a multiplicação microbiana e facilitar os processos de resfriamento e congelamento. É feito principalmente por imersão em tanques de aço inoxidável, equipados com rosca sem fim, contendo mistura de água e gelo, chamados de chiller. Para que o pré-resfriamento seja feito de forma eficiente e adequada, alguns parâmetros devem ser monitorados, dentre eles: a renovação adequada, a temperatura e o sentido contracorrente da água, os níveis adequados de cloro livre, o tempo adequado de passagem da carcaça e a carga bacteriana inicial (NORTHCUTT et al., 2008; CAVANI et al., 2010).

Diversas ferramentas têm sido utilizadas com intuito de garantir o controle sobre esses processos, com destaque para o sistema de Análise de Perigos e Pontos Críticos de Controle (APPCC). Esse sistema visa a identificar qualquer possível perigo que esteja associado à segurança dos alimentos, seja ele microbiológico, físico ou químico. Após a identificação dos perigos, são estabelecidos parâmetros de controle para evitar ou diminuir os riscos associados e definidos os Pontos de Controle (PC) e Pontos Críticos de Controle (PCC). O PC é definido quando o risco de contaminação é baixo e não há possibilidade de ocorrerem riscos inaceitáveis, como alterações de cor, sabor e embalagem. O PCC é um ponto, uma etapa ou um procedimento em que, por uma ação de controle apropriada, um perigo para a segurança alimentar pode ser evitado, eliminado ou reduzido a um nível aceitável. Como exemplos de PCC, podem ser citados processos de cozimento, resfriamento e prevenção de contaminação cruzada (PASTER, 2006).

Na RDC no 12, de 2 de janeiro de 2001, emitida pela Agência Nacional de Vigilância Sanitária (ANVISA) (BRASIL, 2001), é determinado que a avaliação de lotes ou partidas de produtos seja feita adotando-se os planos estatísticos mínimos (planos de três classes). Somente em casos especiais, em que não se pode realizar o plano de três classes, é dispensada a amostragem estatística e procede-se à colheita de uma amostra indicativa, aplicando o plano de duas classes.
Pelo plano de três classes, o lote de um produto pode ser classificado como Aceitável, Aceitável qualidade intermediária ou Inaceitável, enquanto, no plano de duas classes, as unidades amostrais podem ser classificadas como Aceitável ou Inaceitável.

O único padrão microbiológico definido pela legislação para carne de aves in natura é para coliformes termotolerantes (BRASIL, 2001). Segundo o plano de três classes, o número de amostras analisadas para avaliação de um lote de carne de frango é igual a cinco, sendo que até três amostras podem ter resultados entre $5 \times 10^{3}$ e $1 \times 10^{4}$ Unidades Formadoras de Colônia (UFC) $\mathrm{g}^{-1}$ ou Número mais Provável (NMP) $g^{-1}$ para serem consideradas de qualidade intermediária. Resultados inferiores a $5 \times 10^{3} \mathrm{UFC} \mathrm{g}^{-1} \mathrm{ou}$ NMP g ${ }^{-1}$ classificam o lote como Aceitável e superiores a $10^{4} \mathrm{UFC} \mathrm{g}^{-1}$ ou NMP g ${ }^{-1}$ classificam como Inaceitável. No plano de duas classes, o limite é de $1 \times 10^{4} \mathrm{UFC} \mathrm{g}^{-1}$ ou NMP g-1 quando o número de amostras analisadas é menor que cinco.

Embora a eficácia do pré-resfriamento no processamento tecnológico de aves seja um tema de suma importância, pouco é documentado no Brasil sobre essa etapa do abate (LOPES et al., 2007; RODRIGUES et al., 2008; CAVANI et al., 2010; SOUZA et al., 2012). Em relação aos trabalhos que abordaram o tema (CARVALHO et al., 2005; RALL et al., 2009), apesar de utilizarem a legislação nacional como base para metodologia e discussão, ainda não foi publicado um estudo referente ao plano de amostragem oficial para composição das amostras. A utilização desse plano permitirá uma harmonização com o que é praticado no controle de qualidade na indústria e no comércio.

O objetivo deste trabalho foi comparar a análise individual (plano de duas classes) e a análise por lotes (plano de três classes), priorizada pelo plano amostragem oficial da ANVISA, na influência do pré-resfriamento de carcaças de frangos de corte na redução da contaminação por coliformes termotolerantes.

\section{MATERIAL E MÉTODOS}

Foram coletadas aleatoriamente, em dois pontos do processamento, 120 carcaças de frangos antes e 120 após a etapa de pré-resfriamento, totalizando 240 carcaças. A amostragem foi feita de acordo com a RDC n⿳ำ 12, de 2 de janeiro de 2001, da ANVISA (BRASIL, 2001), em cada dia de coleta foi analisado um lote, sendo cinco carcaças por etapa, totalizando 24 lotes. As coletas foram realizadas em Matadouro de Aves sob o Serviço de Inspeção 
Federal (SIF), no Estado de Minas Gerais, no período de outubro de 2009 a abril de 2010. Nas datas das coletas, todos os parâmetros de renovação de água (1 a 2 litros de água por carcaça), temperatura da água do tanque de pré-resfriamento (não superior a $4^{\circ} \mathrm{C}$ ), temperatura da carcaça na saída do tanque (não superior a $7^{\circ} \mathrm{C}$ ) e teor de cloro (máximo de 5 ppm de cloro livre) estiveram dentro daqueles estabelecidos pela legislação (BRASIL, 1998). Após serem coletadas, as carcaças foram acondicionadas sob refrigeração e transportadas para o Laboratório de Controle de Qualidade da empresa, onde foram realizadas as análises.

De cada carcaça, foi retirada uma alíquota de $25 \mathrm{~g}$ de pele e músculo das regiões pericloacal, asa e pescoço, colocadas em sacos plásticos esterilizados, contendo $225 \mathrm{~mL}$ de solução salina peptonada (SSP) a $0,1 \%$ e homogeneizadas por agitação durante um minuto. Deu-se prosseguimento às análises utilizando a técnica de contagem de coliformes termotolerantes em alimentos de acordo com a metodologia recomendada pela Instrução Normativa no 62 do Ministério da Agricultura, Pecuária e Abastecimento (BRASIL, 2003).

As médias das contagens obtidas foram expressas em logaritmos na base $10\left(\log _{10}\right)$ e submetidas à análise não paramétrica pelo teste de Mann-Whitney. Para verificar se houve variação nas médias dos resultados obtidos durante os diferentes períodos de coleta, foi utilizado o teste não paramétrico de Kruskal-Wallis. Os resultados foram interpretados segundo os critérios definidos na legislação para aceitação de carcaças de aves resfriadas ou lotes desses produtos (BRASIL, 2001). Na análise dos lotes, foram consideradas as classificações Aceitável e Aceitável de qualidade intermediária como uma única classe na realização dos cálculos estatísticos. Foi utilizado o teste exato de Fisher para verificar diferenças entre as classes e Odds Ratio (OR), a fim de verificar a chance de aceitação dos lotes antes e após o pré-resfriamento. Foi utilizado o programa GraphPad InStat versão 3.10 em todas as análises estatísticas, com intervalo de confiança fixado em 95\%.

\section{RESULTADOS E DISCUSSÃO}

As médias obtidas das contagens de todas as carcaças coletadas antes e após o pré-resfriamento foram diferentes $(\mathrm{P}<0,0001)$. Antes do pré-resfriamento, a média das contagens foi de $5,0 \times 10^{3}\left(3,71 \log _{10}\right)$ UFC $\mathrm{g}^{-1}$ de coliformes termotolerantes e, depois do pré-resfriamento, foi de $5,1 \times 10^{2}\left(2,71 \log _{10}\right) \mathrm{UFC} \mathrm{g} \mathrm{g}^{-1}$. Foi observada uma redução média de $0,99 \log _{10}$ UFC $\mathrm{g}^{-1}$ de coliformes termotolerantes, ou seja, uma redução de aproximadamente $90 \%$ da contaminação (Tabela 1). LOPES et al. (2007) não verificaram redução significativa de coliformes termotolerantes em carcaças de frango após a passagem nos chillers, apesar de ter havido diminuição. No entanto, pesquisas posteriores evidenciaram diminuição significativa da contaminação por coliformes termotolerantes (RODRIGUES et al., 2008; CAVANI et al., 2010; SOUZA et al., 2012). Pesquisas realizadas em outros países também concluíram que o chiller é capaz de reduzir significativamente a contaminação por coliformes, com reduções de aproximadamente $1 \log _{10}$ UFC g-1 (BILGILI et al., 2002; CASON et al., 2004; NORTHCUTT et al., 2008). Os resultados de mitigação da contaminação observados no presente trabalho foram creditados ao processo de préresfriamento por imersão em água clorada, refrigerada e constantemente renovada, que atuou como um fator determinante na redução da contaminação superficial de carcaças.

Ao comparar as médias para cada mês de coleta, não houve diferença, tanto antes $(\mathrm{P}=0,31)$ quanto após $(\mathrm{P}=0,61)$ o pré-resfriamento (Tabela 1$)$. Com isso, ficou demonstrada uma regularidade no processo de produção da indústria, pois o valor das contagens foi similar durante todo o período estudado. O controle eficiente do sistema de pré-resfriamento é muito importante para que seja obtida melhoria na qualidade microbiológica de carcaças (JAMES et al., 2006).

$\mathrm{Na}$ análise dos resultados individuais das carcaças antes do pré-resfriamento, 83,3\% puderam ser classificadas na categoria Aceitável, enquanto $100 \%$ tiveram a classificação após o pré-resfriamento (Tabela 2), demonstrando a importância decisiva dessa etapa do processamento na descontaminação de carcaças por coliformes. Pesquisas anteriores se baseiam somente nas análises individuais, não utilizando o plano oficial de amostragem para julgamento de lotes dos produtos, que considera como representativa a análise de cinco unidades amostrais (LOPES et al., 2007; RODRIGUES et al., 2008; CAVANI et al., 2010; SOUZA et al., 2012). Ao analisar os resultados baseados na amostragem representativa dos lotes, com o plano de três classes (BRASIL, 2001), 45,8\% (11/24) dos lotes antes do pré-resfriamento foram compatíveis com a classificação Aceitável, 12,5\% (3/24) com classificação Aceitável de qualidade intermediária e 41,7\% (10/24) com classificação Inaceitável. Após o pré-resfriamento, 95,8\% (23/24) dos lotes se enquadraram na classificação Aceitável e 4,2\% (1/24) na classificação Aceitável de qualidade intermediária. 
Tabela 1 - Resultados da contagem de coliformes termotolerantes em diferentes lotes de carcaças de frangos em matadouro avícola sob Serviço de Inspeção Federal (SIF), no período de outubro de 2009 a abril de 2010.

\begin{tabular}{lcc}
\hline Mês & $\begin{array}{c}\text { Antes do pré-resfriamento } \\
\left(\log _{10} \mathrm{UFC} \mathrm{g}^{-1}\right)\end{array}$ & $\begin{array}{c}\text { Após o pré-resfriamento } \\
\left(\log _{10} \mathrm{UFC} \mathrm{g}^{-1 \mathrm{I}}\right)\end{array}$ \\
\hline Out/2009 & $3,73^{\mathrm{a}}$ & $2,95^{\mathrm{b}}$ \\
Nov/2009 & $3,48^{\mathrm{a}}$ & $2,46^{\mathrm{b}}$ \\
Dez/2009 & $3,77^{\mathrm{a}}$ & $2,52^{\mathrm{b}}$ \\
Jan/2010 & $3,88^{\mathrm{a}}$ & $2,38^{\mathrm{b}}$ \\
Fev/2010 & $3,49^{\mathrm{a}}$ & $2,48^{\mathrm{b}}$ \\
Mar/2010 & $3,69^{\mathrm{a}}$ & $3,13^{\mathrm{b}}$ \\
Abr/2010 & $3,67^{\mathrm{a}}$ & $2,42^{\mathrm{b}}$ \\
Média & $3,71^{\mathrm{A}}$ & $2,71^{\mathrm{B}}$ \\
\hline
\end{tabular}

${ }^{\mathrm{I}}$ Média dos resultados individuais a partir da amostragem de cinco aves (UFC g ${ }^{-1}$ ). As médias identificadas com a mesma letra ( $\mathrm{a}-\mathrm{P}=0,31 ; \mathrm{b}$ - $\mathrm{P}=0,61$ ) não diferem entre si pelo teste de Kruskal-Wallis/Dunn.

${ }^{\text {II }}$ Mann-Whitney; A, B = letras diferentes na mesma linha expressam diferenças significativas entre si $(\mathrm{P}<0,0001)$.

Houve forte associação entre a aceitabilidade dos lotes e a passagem pelo chiller com um valor de OR de 35,48 ( $\mathrm{P}=0,0006$; IC 95\% 1,93-652,09), ou seja, as chances de um lote ser aceitável (somatório dos lotes Aceitável e Aceitável de qualidade intermediária) foram 35 vezes maiores após o pré-resfriamento que antes dessa etapa, comprovando a grande relevância do processo de pré-resfriamento na descontaminação de carcaças (Tabela 2).

Houve grande diferença quando comparadas a interpretação dos resultados pela análise individual (plano de duas classes) e pela análise por lotes (plano de três classes), pois haveria rejeição de 16,7\% (20/120) das carcaças pela análise individual e 41,7\% (50/120) das carcaças pela análise por lotes. Portanto, como os trabalhos de pesquisa utilizam a interpretação individual (CARVALHO et al., 2005; RALL et al., 2009), os resultados podem estar subestimados quando se considera o plano de amostragem recomendado pela legislação (BRASIL, 2001).

A etapa de pré-resfriamento das carcaças é definida como um Ponto de Controle (PC) pela Circular no 668/2006 (BRASIL, 2006), que estabelece o plano básico de APPCC para indústrias de produtos de origem animal. Considerando que no presente trabalho houve uma redução significativa no número de coliformes termotolerantes em carcaças de frango a limites aceitáveis e como não há nenhuma outra etapa que garanta redução na contaminação das carcaças após o pré-resfriamento, deve ser considerado um Ponto Crítico de Controle nos planos APPCC das indústrias, como também sugerido por BILGILI et al. (2002) e RODRIGUES et al. (2008). Com isso, haverá maior controle sobre o processo, garantindo a eficácia do sistema.

\section{CONCLUSÃO}

A contaminação por coliformes termotolerantes em carcaças de frango sofreu importante redução após sua passagem pela etapa de pré-resfriamento, sendo decisiva para a aceitação dos lotes para comercialização pelos parâmetros vigentes na legislação nacional.

É importante que trabalhos futuros sejam realizados com amostragem baseada no plano de três classes, uma vez que a utilização do plano de duas classes tende a subdimensionar os resultados, se comparados aos que seriam obtidos em ação fiscal no comércio.

Tabela 2 - Classificação segundo critérios microbiológicos definidos na legislação (BRASIL, 2001) para amostras de carcaças de frangos em matadouro avícola, sob Serviço de Inspeção Federal (SIF) antes e após o pré-resfriamento.

\begin{tabular}{|c|c|c|c|c|c|c|c|c|}
\hline \multirow{2}{*}{ Classificação } & \multicolumn{4}{|c|}{ 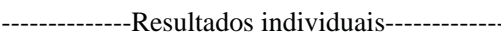 } & \multicolumn{4}{|c|}{---Resultados por lotes ${ }^{3}--$} \\
\hline & Antes $^{1}$ & $\%$ & Após ${ }^{2}$ & $\%$ & Antes $^{1}$ & $\%$ & Após ${ }^{2}$ & $\%$ \\
\hline Aceitável & 100 & 83,3 & 120 & 100,0 & 11 & 45,8 & 23 & 95,8 \\
\hline Aceitável de qualidade intermediária & - & - & - & - & 3 & 12,5 & 1 & 4,2 \\
\hline Inaceitável & 20 & 16,7 & 0 & 0,0 & 10 & 41,7 & 0 & 0,0 \\
\hline
\end{tabular}

${ }^{1}$ Antes do pré-resfriamento. ${ }^{2}$ Após o pré-resfriamento.

${ }^{3} \mathrm{OR}=35,48$ (P=0,0006; IC 95\% 1,93; 652,09). Os lotes de classificação Aceitável e Aceitável de qualidade intermediária foram analisados como um único grupo. 


\section{REFERÊNCIAS}

BILGILI, S.F. et al. Visible ingesta on prechill carcasses does not affect the microbiological quality of broiler carcasses after immersion chilling. Journal of Applied Poultry Research, v.11, p.233-238, 2002. Disponível em: <http://japr.fass.org/ content/11/3/233.full.pdf>. Acesso em: 17 set. 2011.

BRASIL. Circular no 668, de 19 de setembro de 2006. Diretrizes para preparação de Plano de APPCC (HACCP) para o processo de abate de aves. Ministério da Agricultura, Pecuária e Abastecimento. Brasília, DF, 19 set. 2006. Acesso em: 07 jul. 2012. Online. Disponível em: <http://www.abef.com.br/Legislacoes/Circular6682006.pdf>.

BRASIL. Instrução normativa nº 62, de 26 de agosto de 2003. Métodos analíticos oficiais para análises microbiológicas para o controle de produtos de origem animal e água. Diário Oficial da União, Ministério da Agricultura, Pecuária e Abastecimento. Brasília, DF, 18 set. 2003.

BRASIL. Instrução normativa $n^{\circ}$ 210, de 10 de novembro de 1998. Regulamento Técnico da Inspeção Tecnológica e HigiênicoSanitária de Carne de Aves. Diário Oficial da União, Ministério da Agricultura, Pecuária e Abastecimento. Brasília, DF, 26 nov. 1998.

BRASIL. RDC $n^{0}$ 12, de 2 de janeiro de 2001. Aprova o Regulamento Técnico sobre Padrões Microbiológicos para Alimentos. Diário Oficial da União, Ministério da Saúde, Agência Nacional de Vigilância Sanitária. Brasília, DF, 10 jan. 2001.

CARVALHO, A.C.F.B. et al. Presença de microrganismos mesófilos, psicrotróficos e coliformes em diferentes amostras de produtos avícolas. Arquivos do Instituto Biológico, São Paulo, v.72, p.303307, 2005. Disponível em: <http://www.biologico.sp.gov.br/docs/ arq/V72_3/carvalho.PDF>. Acesso em: 20 jul. 2012.

CASON, J.A. et al. Effect of prechill fecal contamination on numbers of bacteria recovered from broiler chicken carcasses before and after immersion chilling. Journal of Food Protection, v.67, p.1829-1833, 2004. Disponível em: <http://www.ncbi.nlm. nih.gov/pubmed/15453571>. Acesso em: 17 set. 2011.

CAVANI, R. et al. Comparison of microbial load in immersion chilling water and poultry carcasses after 8, 16 and 24 working hours. Ciência Rural, v.40, p.1603-1609, 2010. Disponível em: <http://dx.doi.org/10.1590/S0103-84782010005000115>. Acesso em: 13 set. 2011. doi: 10.1590/S0103-84782010005000115.
JAMES, C. et al. The primary chilling of poultry carcasses-a review. International Journal of Refrigeration, v.29, p.847-862, 2006. Disponível em: <http://www.sciencedirect.com/science/ article/pii/S0140700705001441>. Acesso em: 27 nov. 2012.

JAY, J.M. Modern food microbiology. 6.ed. Gaithersburg (MD): Aspen Publishers, 2000. 720 p.

LOPES, M. et al. Pesquisa de Salmonella spp. e microrganismos indicadores em carcaças de frango e água de tanques de préresfriamento em abatedouro de aves. Semina: Ciências Agrárias, v.28, p.465-476, 2007. Disponível em: <http://www.uel.br/ revistas/uel/index.php/semagrarias/article/view/2989>. Acesso em: 13 set. 2011.

NORTHCUTT, J.K. et al. Microbiology of broiler carcasses and chemistry of chiller water as affected by water reuse. Poultry Science, v.85, p.1458-1463, 2008. Disponível em: <http://ps.fass. org/content/87/7/1458.long $>$. Acesso em: 26 ago. 2012. doi: 10.3382/ps.2007-00480.

PASTER, T. The HACCP food safety training manual. New Jersey : John Wiley \& Sons, 2006. 352p.

RALL, V.L.M. et al. Pesquisa de Salmonella e das condições sanitárias em frangos e lingüiças comercializados na cidade de Botucatu. Brazilian Journal of Veterinary Research and Animal Science, v.46, p. 167-174, 2009. Disponível em: <http:// www.revistasusp.sibi.usp.br/pdf/bjvras/v46n3/v46n3a01.pdf>. Acesso em: 26 ago. 2012.

RODRIGUES, A.C.C. et al. Análise e monitoramento de pontos críticos no abate de frangos utilizando indicadores microbiológicos. Ciência Rural, v.38, p.1948-1953, 2008. Disponível em: <http:// dx.doi.org/10.1590/S0103-84782008000700023>. Acesso em: 13 set. 2011. doi: 10.1590/S0103-84782008000700023.

SOUZA, L.C.T. et al. Microbiological evaluation of chicken carcasses in an immersion chilling system with water renewal at 8 and 16 hours. Journal of Food Protection, v.75, p.973975, 2012. Disponível em: <http://www.ncbi.nlm.nih.gov/ pubmed/22564950>. Acesso em: 24 ago. 2011.

UNIÃO BRASILEIRA DE AVICULTURA (UBABEF). Relatório anual 2010-2011. Acesso em: 12 jul. 2012. Online. Disponível em: <http://www.abef.com.br/ubabef/publicacoes_ relatoriosanuais.php $>$. 